\title{
Adverse Drug Events Related to Canagliflozin: A Meta-Analysis of Randomized, Placebo-Controlled Trials
}

Shawaqfeh MS*, Bhinder MT, Halum AS, Harrington C, Muflih S and Do T

Nova Southeastern University, Palm Beach Gardens, Florida, United States

\begin{abstract}
Canagliflozin, a sodium-glucose co-transporter 2 (SGLT2) inhibitor, was recently approved in United States for the treatment of type 2 diabetes mellitus in combination with diet and exercise. Two strengths were approved, 100 $\mathrm{mg}$ and $300 \mathrm{mg}$. The US label warns of a dose-dependent increase in volume depletion-related adverse reactions on the $300 \mathrm{mg}$ dose. The purpose of this meta-analysis was to assess the dose response of canaglifozin on safety and tolerability outcomes.

A search was performed through MEDLINE, EMBASE, and Cochrane Library for clinical trials comparing canagliflozin with placebo or active controls. Keywords include canagliflozin, and meta-analysis. Reference lists of relevant articles were also used as sources. Two reviewers extracted data and evaluated pertinent studies. Study characteristics, safety outcomes of interest, and risk of bias were collected, verified and further analyzed. Canagliflozin was studied as monotherapy in 2 trials $(n=270)$ and as an add-on therapy in 10 studies $(n=2525)$. Ten of the studies were included in the analysis of selected safety outcomes. Length of intervention ranged from 12 to 52 weeks. All studies were randomized, comparative to either placebo or active controls. Canagliflozin treatment, increased the risk of vulvovaginal mycotic infection (RR 4.11; Cl 3.01-5.60; $\mathrm{P}<0.01)$, pollakiuria (RR 2.89, $\mathrm{Cl} 1.84$ 4.53), polyuria (RR 3.87; Cl 1.66-9.05), hypoglycemia (RR 1.22; Cl 1.10-1.35) and hypovolemia (RR 2.04; $\mathrm{Cl} 1.13-$ 3.68). There were no significant dose responses among observed safety outcomes with the exception of genital infections (RR 4.12; $\mathrm{Cl} 2.47-6.87$ ). Additionally, the canagliflozin treatment group experienced a $24 \%$ reduction in serious adverse events when compared to controls (RR 0.76; 0.62-0.93; $\mathrm{P}<0.01$ ).
\end{abstract}

This meta-analysis did not show a dose response effect of canaglifozin on treatment emergent adverse events in type 2 diabetics.

Keywords: Canagliflozin; Meta-analysis; Diabetes; Adverse events

\section{Introduction}

Diabetes Mellitus is fast becoming one of the most prevalent chronic diseases in the United States, with $14.3 \%$ of the population over 20 years of age suffering from this malady [1]. Patients are educated about the importance of having a multi-pronged approach in management of their disease, where one combines diet and exercise regimens with medications. Due to the constant advancement in medical research and innovation, new treatment regimens are constantly being invented to keep pace with the demand for better antidiabetic medications. As with any drug therapy regimen, there has to be a balance between its effectiveness and tolerability, and this is no different for new antidiabetic medications such as canagliflozin; a sodium-glucose co-transporter 2 (SGLT2) inhibitor. The drug, was the first of its kind (SGLT2s) to be approved for treatment of Type 2 Diabetes Mellitus in the United States $[2,3]$. These questions were answered in several clinical studies variably; this analysis will compile all these reports together in one report that will strengthen the evidence of adverse events reporting.

The drug is to be used as an adjunct with diet, exercise, and other antidiabetic drug classes. There are $100 \mathrm{mg}$ and $300 \mathrm{mg}$ strengths dosage approved, with the former being the starting dosage, incremented to the latter in patients who have normal renal function. Drug label warns of a dose-dependent increase in volume depletion-related adverse reactions on the $300 \mathrm{mg}$ dose [4] the purpose of this meta-analysis is to assess the occurrence of drug-related adverse events associated with the use of canagliflozin at varying doses. The meta-analysis will have all randomized controlled trials that reported adverse events in a systematic way combined in one report that will verify the significance of dose related adverse events. This type of information will help the clinicians to decide safely about the appropriateness of their selection of canagliflozin.

\section{Method}

A systematic review was performed from September 2013-July 2015 using the EMBASE and MEDLINE databases, identifying Cochrane reviews, controlled clinical trials, randomized control trials, meta-analyses and systematic reviews, using search terms canagliflozin, placebo, adverse events, and humans. The studies were limited to those published in the English language, and conducted on humans. The Trial Registry website ClinicalTrials.gov was also searched for studies relating to canagliflozin.

The pertinent data describing adverse events was extracted from the safety results sections of the articles, including relevant text and tables. This data was then subsequently entered into Review Manager Software, Version 5.3 (The Nordic Cochrane Centre, The Cochrane Collaboration, and Copenhagen, Denmark) for analysis [5]. The

*Corresponding author: Shawaqfeh MS, Nova Southeastern University Palm Beach Gardens, Florida, United States, Tel: 56-805-2243; E-mail: mshawaqfeh@nova.edu

Received December 02, 2015; Accepted December 10, 2015; Published December 12, 2015

Citation: Shawaqfeh MS, Bhinder MT, Halum AS, Harrington C, Muflih S, et al. (2015) Adverse Drug Events Related to Canagliflozin: A Meta-Analysis of Randomized, Placebo-Controlled Trials. Adv Pharmacoepidemiol Drug Saf 4: 196 doi:10.4172/2167-1052.1000196

Copyright: $\odot 2015$ Shawaqfeh MS, et al. This is an open-access article distributed under the terms of the Creative Commons Attribution License, which permits unrestricted use, distribution, and reproduction in any medium, provided the original author and source are credited. 
Citation: Shawaqfeh MS, Bhinder MT, Halum AS, Harrington C, Muflih S, et al. (2015) Adverse Drug Events Related to Canagliflozin: A Meta-Analysis of Randomized, Placebo-Controlled Trials. Adv Pharmacoepidemiol Drug Saf 4: 196. doi:10.4172/2167-1052.1000196

Page 2 of 6

aforementioned software has been made available by the Cochrane Collaboration to facilitate meta-analyses.

The data was combined for meta-analysis employing the MantelHaenszel method, random effects model at 95\% confidence for the RR. Study characteristics and safety outcomes of interest were collected, verified and further analyzed, focusing on the frequencies of dose dependent adverse events for both the canagliflozin group and the placebo populations.

\section{Results}

\section{Description of the included studies}

In the initial stages of the study, there were 678 citations which were subjected to elemental review (Figure 1). Of those studies, randomized, placebo-controlled trials which described data on doserelated adverse events in adult patients taking canagliflozin were sent for further analysis while the others, which did not contain relevant information on adverse reactions, or did not have a placebo control were not included. Following this elemental review, there were 49 articles which were used for adverse event data extraction. Of those articles, 19 were included in the final analysis [6-24]. All of the studies were randomized, placebo controlled trials and one was the US label for brand name canagliflozin (Invokana; Janssen Pharmaceuticals, Inc., Titusville, NJ) [4].

All studies were conducted in adults, from varying centers in over 22 different countries around the world. The studies varied in length from 4 weeks up to 104 weeks. The trials included a total of 8932 patients, with population sizes ranging from 10-1452 patients in each trial. Canagliflozin doses ranged from $10 \mathrm{mg}-800 \mathrm{mg} /$ day.

\section{Any adverse event}

The overall rate of adverse events (Tables 1 and 2) in both the canagliflozin group and the placebo group were similar with the exception of a few adverse events. Furthermore, there was no dose-

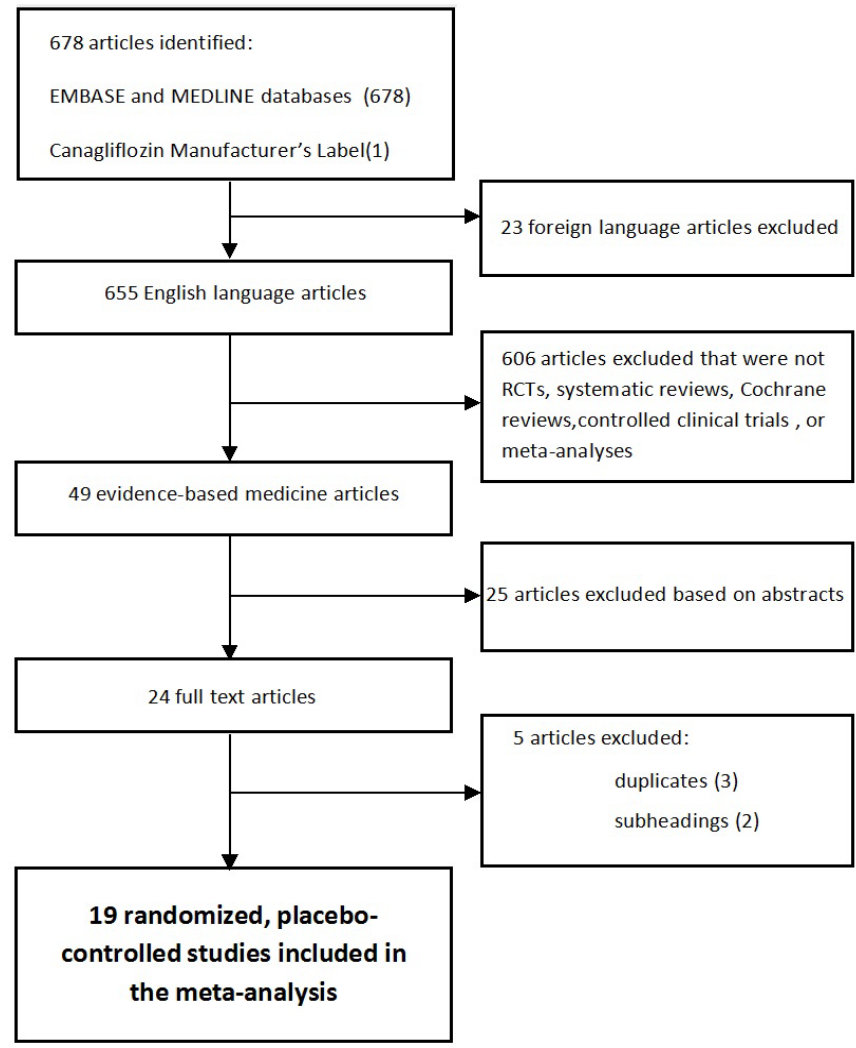

Figure 1: Schematic of search strategy. RCT=Randomized Control Trial.

Table 1: Treatment-emergent adverse events of canagliflozin $100 \mathrm{mg}$ vs. control.

\begin{tabular}{|c|c|c|c|c|c|c|}
\hline \multirow{2}{*}{ Adverse Event } & \multirow{2}{*}{ No. of Studies } & \multicolumn{2}{|c|}{ No. of Patients } & \multicolumn{2}{|c|}{ Adverse Event Rate (\%) } & \multirow{2}{*}{\begin{tabular}{|l|} 
Risk Ratio \\
M-H, Random, 95\%
\end{tabular}} \\
\hline & & Drug & Control & Drug & Control & \\
\hline Any Adverse Event & 16 & 2521 & 2512 & 65 & 64 & $1.02[0.98,1.06]$ \\
\hline Serious Adverse Event & 15 & 2737 & 2725 & 6.2 & 7.2 & $0.86[0.71,1.04]$ \\
\hline $\begin{array}{l}\text { AEs Leading to } \\
\text { Discontinuation }\end{array}$ & 14 & 2496 & 2488 & 4 & 3.9 & $1.01[0.74,1.39]$ \\
\hline Postural Dizziness & 8 & 1495 & 1480 & 0.87 & 0.675 & $1.20[0.54,2.68]$ \\
\hline Hypovolamia & 7 & 1505 & 1497 & 1.32 & 0.46 & $2.52[1.10,5.78]$ \\
\hline Polyuria & 5 & 1377 & 1367 & 0.726 & 0.14 & $3.22[0.86,12.02]$ \\
\hline Pollakiuria & 7 & 1505 & 1497 & 3.5 & 0.868 & $3.30[1.48,7.37]$ \\
\hline Hypoglycaemia & 11 & 1446 & 1435 & 15.97 & 11.2 & $1.40[1.18,1.66]$ \\
\hline $\begin{array}{l}\text { Vulvovaginal Mycotic } \\
\text { Infection }\end{array}$ & 9 & 781 & 741 & 12.03 & 2.56 & $4.24[2.65,6.78]$ \\
\hline Genital Mycotic Infections & 13 & 1678 & 1709 & 7.15 & 1.87 & $3.57[2.40,5.32]$ \\
\hline Nasopharyngitis & 4 & 295 & 294 & 3.72 & 6.12 & $0.69[0.31,1.52]$ \\
\hline Nausea & 4 & 231 & 228 & 4.32 & 2.19 & $1.68[0.61,4.66]$ \\
\hline Headache & 4 & 231 & 228 & 10.3 & 5.26 & $1.82[0.94,3.54]$ \\
\hline Diarrhea & 4 & 231 & 228 & 2.16 & 4.38 & $0.51[0.19,1.41]$ \\
\hline Urinary Tract Infection & 13 & 2422 & 2413 & 6.85 & 5.71 & $1.20[0.96,1.49]$ \\
\hline Urinary Tract AEs & 2 & 128 & 130 & 9.375 & 6.92 & $1.35[0.59,3.10]$ \\
\hline Postural Hypotension & 6 & 1441 & 1432 & 0.55 & 0.13 & $2.94[0.81,10.75]$ \\
\hline $\begin{array}{l}\text { Osmotic Diuresis-Related } \\
\text { AEs }\end{array}$ & 5 & 827 & 823 & 5.68 & 2.67 & $1.98[1.02,3.84]$ \\
\hline Volume-Related AEs & 5 & 824 & 827 & 3.03 & 1.45 & $2.09[1.03,4.23]$ \\
\hline
\end{tabular}

$I^{2}$ Index (\%) $=<50 \%$ 
Table 2: Treatment-emergent adverse events of canagliflozin $300 \mathrm{mg}$ vs. control.

\begin{tabular}{|c|c|c|c|c|c|c|}
\hline \multirow{2}{*}{ Adverse Event } & \multirow{2}{*}{ No. of Studies } & \multicolumn{2}{|c|}{ No. of Patients } & \multicolumn{2}{|c|}{ Adverse Event Rate (\%) } & \multirow{2}{*}{\begin{tabular}{|l} 
Risk Ratio \\
M-H, Random, 95\%
\end{tabular}} \\
\hline & & Drug & Control & Drug & Control & \\
\hline Any Adverse Event & 18 & 2836 & 2835 & 67 & 65 & $1.02[0.99,1.06]$ \\
\hline Serious Adverse Event & 15 & 3019 & 3010 & 6.29 & 7.17 & $0.89[0.74,1.07]$ \\
\hline AEs Leading to Discontinuation & 14 & 2783 & 2773 & 5.19 & 3.85 & $1.32[1.03,1.69]$ \\
\hline Postural Dizziness & 8 & 1857 & 1843 & 0.8 & 0.67 & $1.31[0.58,2.98]$ \\
\hline Hypovolemia & 8 & 1879 & 1875 & 0.9 & 0.54 & $1.63[0.70,3.79]$ \\
\hline Polyuria & 6 & 1751 & 1745 & 1.08 & 0.11 & $4.41[1.45,13.40]$ \\
\hline Pollakiuria & 8 & 1879 & 1875 & 2.92 & 0.96 & $2.64[1.52,4.61]$ \\
\hline Hypoglycaemia & 10 & 1721 & 1713 & 22.3 & 17.5 & $1.32[1.08,1.62]$ \\
\hline Vulvovaginal Mycotic Infection & 10 & 966 & 907 & 11.4 & 2.86 & $3.69[2.45,5.57]$ \\
\hline Genital Mycotic Infections & 13 & 1780 & 1830 & 8.53 & 1.47 & $4.88[3.27,7.28]$ \\
\hline Nasopharyngitis & 5 & 317 & 312 & 4.73 & 6.41 & $0.78[0.41,1.51]$ \\
\hline Nausea & 5 & 244 & 238 & 5.32 & 2.94 & $1.50[0.62,3.61]$ \\
\hline Headache & 4 & 234 & 228 & 6.83 & 5.26 & $1.37[0.57,3.30]$ \\
\hline Diarrhea & 5 & 252 & 246 & 5.15 & 4.47 & $1.13[0.48,2.66]$ \\
\hline Urinary Tract Infection & 13 & 2708 & 2698 & 6.61 & 5.85 & $1.14[0.92,1.40]$ \\
\hline Urinary Tract AEs & 2 & 128 & 130 & 9.37 & 6.92 & $1.35[0.59,3.10]$ \\
\hline Postural Hypotension & 7 & 1815 & 1810 & 0.49 & 0.16 & $1.99[0.70,5.62]$ \\
\hline Osmotic Diuresis-Related AEs & 5 & 829 & 823 & 6.87 & 2.67 & $2.42[1.31,4.48]$ \\
\hline Volume-Related AEs & 4 & 733 & 734 & 3.41 & 1.49 & $2.20[1.08,4.50]$ \\
\hline
\end{tabular}

$I^{2}$ Index $(\%)=<50 \%$

dependent response associated with the development of any particular adverse event, generally being equally present in both cohorts. Additionally, the rate of inconsistency or heterogeneity, measured by $\mathrm{I}^{2}$ was low, with many of the analyses presenting with no inconsistencies at all. The overall rate of any adverse event in the $100 \mathrm{mg}$ Canagliflozin group was $65 \%$ and the $100 \mathrm{mg}$ placebo group was $64 \%$, with a risk ratio of $1.02[0.98,1.06]$. In the $300 \mathrm{mg}$ canagliflozin group, the rate of any adverse event was once again comparable to the placebo at $67 \%$ for the canagliflozin group and $65 \%$ for the placebo group. The risk ratio was $1.02[0.99,1.06]$.

\section{Vulvovaginal mycotic infections/genital mycotic infections}

The adverse events with the highest risk were the vulvovaginal mycotic infections and the genital mycotic infections, which showed a significant difference between the canagliflozin group and the placebo group. The adverse event rate of vulvovaginal mycotic infections (Figure 2) in the $100 \mathrm{mg}$ canagliflozin group was $12 \%$ versus $2.56 \%$ in the placebo group, with a risk ratio of 4.24 [2.65, 6.78]. In the 300 $\mathrm{mg}$ canagliflozin group, the rate of vulvovaginal mycotic infections was $11.4 \%$ and the placebo group had $2.86 \%$, with a RR of 3.69 [2.45, 5.57]. In the $100 \mathrm{mg}$ canagliflozin group, the rate of genital mycotic infections was $7 \%$ versus $1.8 \%$ in the placebo group, RR 3.57 [2.40, 5.32]. In the $300 \mathrm{mg}$ canagliflozin cohort, the rate of genital mycotic infection was $8.53 \%$ versus $1.47 \%$ in the placebo group with a RR of 4.88 [3.27, 7.28].

\section{Osmotic diuresis-related adverse events}

The adverse event rate of osmotic-diuresis related adverse events in the $100 \mathrm{mg}$ group was $5.68 \%$ and $2.67 \%$ for the drug and placebo respectively, RR 1.98 [1.02, 3.84]. In the $300 \mathrm{mg}$ canagliflozin group, the rate of osmotic-diuresis related adverse events was $6.87 \%$ and the placebo group had $2.67 \%$, with a RR of 2.42 [1.31, 4.48].

\section{Volume-related adverse events}

In the $100 \mathrm{mg}$ canagliflozin group, the rate of volume-related adverse events was $3.03 \%$ versus $1.45 \%$ in the placebo group, RR 2.09
[1.03, 4.23] (Figure 3). In the $300 \mathrm{mg}$ canagliflozin cohort, the rate of volume-related adverse events was $3.41 \%$ versus $1.49 \%$ in the placebo group with a RR of $2.20[1.08,4.50]$.

\section{Hypoglycaemia}

The adverse event rate of hypoglycaemia (Figure 4) in the $100 \mathrm{mg}$ canagliflozin group was $15.97 \%$ versus $11.2 \%$ in the placebo group, with a risk ratio of $1.40[1.18,1.66]$. In the $300 \mathrm{mg}$ canagliflozin group, the rate of hypoglycaemia was $22.3 \%$ and the placebo group had $17.5 \%$, with a RR of $1.32[1.08,1.62]$.

\section{Other adverse events}

Urinary tract adverse events had an adverse event rate of $9.375 \%$ in the canagliflozin group and $6.92 \%$ in the placebo group, RR 1.35 [0.59, 3.10]. The adverse event rate of pollakiuria in the $100 \mathrm{mg}$ cohort was $3.5 \%$ for canagliflozin and $0.868 \%$ for the placebo, RR 3.30 [1.48, 7.37].

\section{Discussion}

There were 16 different types of adverse events associated with the use of canagliflozin. Overall, use of canagliflozin did not increase the incidence of any adverse event or serious adverse events. At the higher dose (300 $\mathrm{mg}$ ), there was an increased risk of discontinuation of the drug due to adverse events RR 1.32 [1.03, 1.69]. Both the 100 $\mathrm{mg}$ and $300 \mathrm{mg}$ dose of canagliflozin increased the risk of genital mycotic/vulvovaginal mycotic infections. To a lesser degree was the incidence of urinary tract adverse events. As is common knowledge, patients suffering from Type 2 Diabetes Mellitus are more prone to both urinary tract infections and genital mycotic infections due to a number of different rationale, such as decreased humoral immunity, increased urination, and possible urinary retention/ incontinence due to diabetic neuropathies.

However, when looking at canagliflozin and all SGLT2's role in the development of genital mycotic infections, one must look at its mechanism which facilitates glycosuria, likely a causative factor. It is 
Citation: Shawaqfeh MS, Bhinder MT, Halum AS, Harrington C, Muflih S, et al. (2015) Adverse Drug Events Related to Canagliflozin: A Meta-Analysis of Randomized, Placebo-Controlled Trials. Adv Pharmacoepidemiol Drug Saf 4: 196. doi:10.4172/2167-1052.1000196

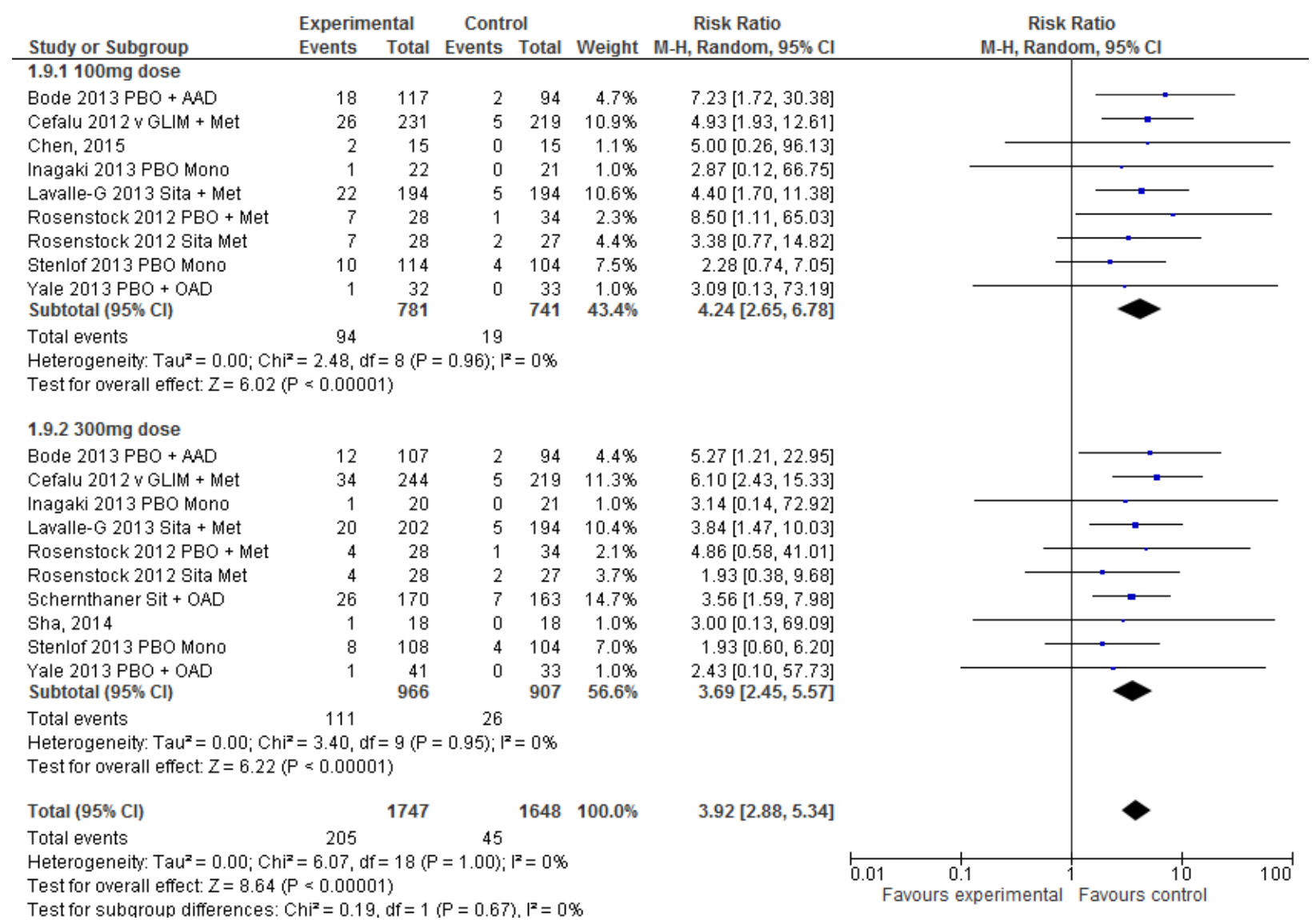

Figure 2: Forest plot of comparison of treatment-emergent vulvovaginal mycotic infection with canagliflozin $100 \mathrm{mg}$ and $300 \mathrm{mg}$.

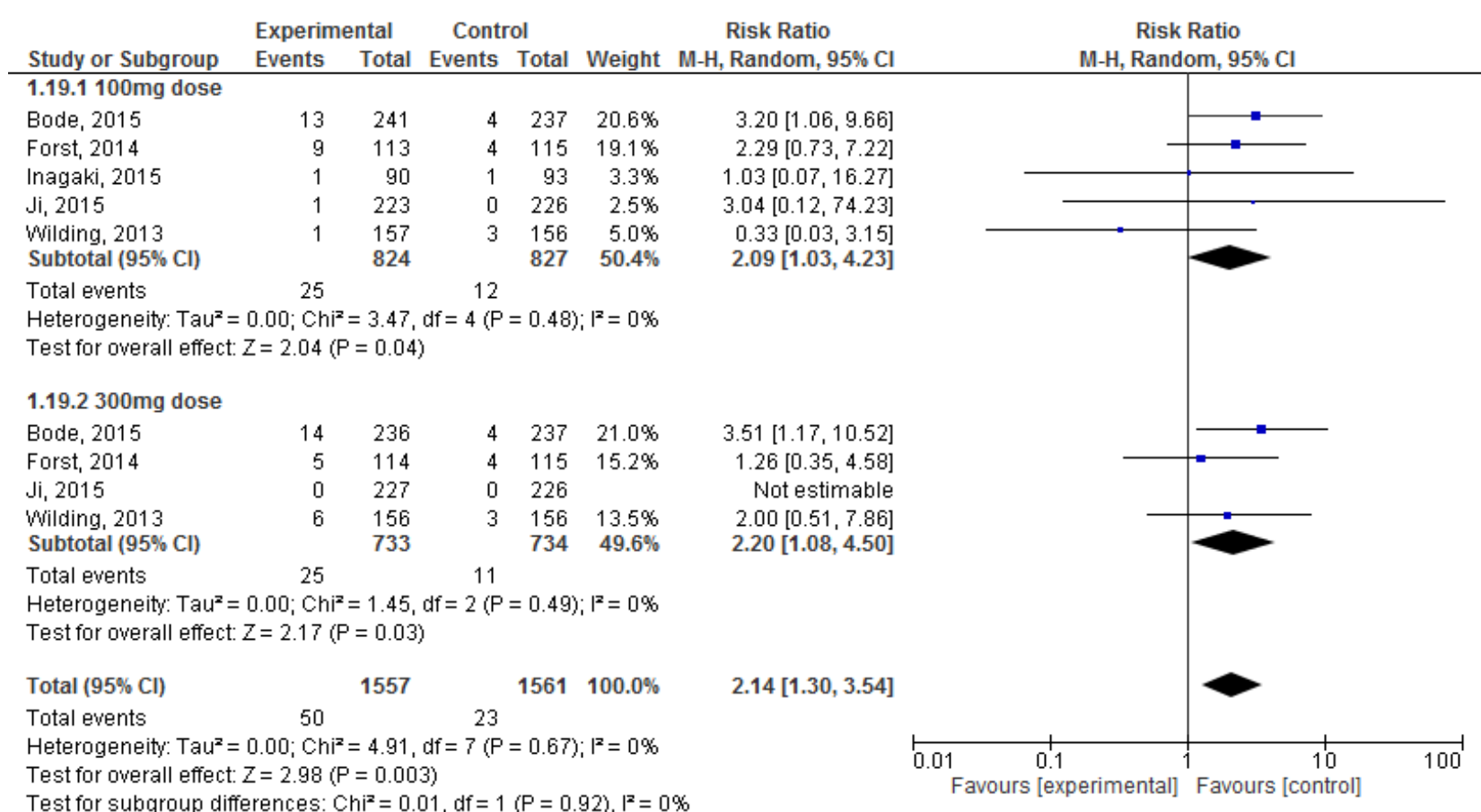

Figure 3: Forest plot of comparison of treatment-emergent volume-related adverse events with canagliflozin $100 \mathrm{mg}$ and $300 \mathrm{mg}$. 


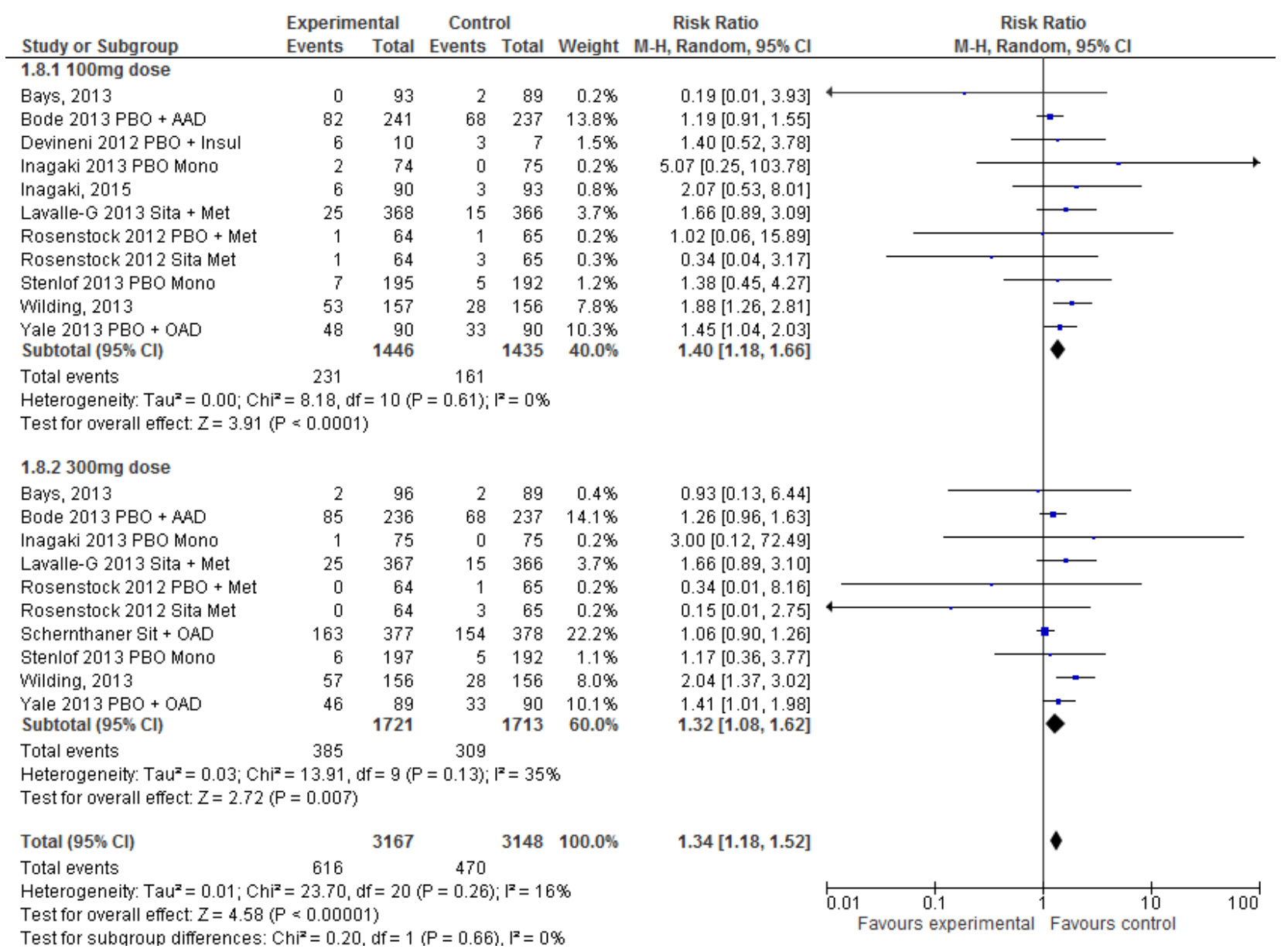

Figure 4: Forest plot of comparison of treatment-emergent hypoglycaemia with canagliflozin $100 \mathrm{mg}$ and $300 \mathrm{mg}$.

purported that glycosuria maintains a welcoming environment for the major hyphal cell wall protein 1 of the fungi to attach to the uroepithelium, grow and multiply. The philosophy behind this is that as the major hyphal wall protein 1 (hwp1) plays an integral role in mating, normal hyphal development, cell-to-cell adhesive functions necessary for biofilm integrity, attachment to host, and virulence, it must be involved in the overall mechanism advanced to describe the phenomenon in question [25]. Furthermore, its properties promote the effective interaction between both fungal and host molecules, which leads to effective colonization, especially when humoral immunity is decreased [25] .

It is possible that, due to the widely acknowledged association of increased urinary tract infections and genital mycotic infections associated with diabetes, that there is increased surveillance leading to increased diagnosis of infections [26]. However, as SGLT2s are associated with an increase in osmotic-diuresis related adverse events such as polyuria and pollakiuria, there could be an increased tendency to report infections in those patients [26].

As with any antidiabetic agent, there is always the possibility of patients experiencing hypoglycaemic attacks. As a result of this, patients should exercise caution whenever taking any hypoglycemic agent, being cognizant of the associated clinical manifestations related to the adverse event, in order to prevent development of serious complications. The FDA approval promotes canagliflozin as an adjunct with other antidiabetics. This might add up some concern about the added risks and safety issues in elderly.

It has been reported by the FDA that canagliflozin is associated with an increased risk for bone fractures, thus causing the mentioned organisation to strengthen its warning for the drug [20]. This information is based on new confirmatory information from nine clinical trials [20]. The logic behind the development of these fractures stems from the fact that SGLT2 inhibitors increase serum concentrations of phosphate through increased tubular resorption, which has the potential to adversely affect bone. These inhibitors also increase the concentration of parathyroid hormone, which enhances bone resorption, thus increasing the risk of pathologic fractures [20]. In the included studies of this meta-analysis, there was no reported data relating to the association of canagliflozin with bone fractures. This could be due to the fact that the number of cases is not significant, and, therefore, the results were not included in the studies.

Canagliflozin showed in various studies almost an increasing number of adverse events that was not clearly stating whether these events are dose related or not. But this analysis compiled all reported data from all strictly randomized controlled studies to verify the strength of evidence that the adverse events are dose related or not.

\section{Limitations}

The results in this study are limited to the data that is currently 
available. A limitation of this study could stem from limited sample sizes and treatment durations in some of the included studies, which could affect conclusions pertaining to the safety and efficacy of canagliflozin. Furthermore, the patient populations reflect the strength of the study. In order to represent a true diabetic population, patients from a broad age group and varying ethnicities, especially black or AfricanAmerican and Hispanic populations where diabetes is highly prevalent coupled with overweight and obese patients should have been included in the studies to ensure that the data found can be generalized to the diabetic population as a whole. Also, these trials did not report data for subgroups of high risk patients with low renal function, advanced age, or those taking loop diuretics.

\section{Conclusion}

Canagliflozin has been associated with an increased incidence of genital mycotic infections and vulvovaginal mycotic infections, and to a lesser degree urinary tract infections. While the exact mechanism is not known, it is believed that there could be an interaction between the glycosuria effect of the SGLT2 and the hwp1 which is allowing fungus to grow and flourish in those regions. No dose dependent adverse events were noted, as they were equally prevalent in both dosing cohorts. The risk of hypoglycaemia is increased, as is the case with most of the antidiabetic agents. The risk of volume depletion is significant, and high-risk patients such as the elderly, those with chronic renal failure, or those taking diuretics should be monitored closely if prescribed canagliflozin.

\section{References}

1. Tucker M (2015) Diabetes Prevalence in the US May Have Plateaued. Medscape.

2. http://www.reuters.com/article/johnsonjohnson-diabetesidus|3n0cl1fv20130329

3. American Diabetes Association (2013) Economic Costs of Diabetes in the US in 2012. Diabetes Care. 36: 1033-1046.

4. https://www.invokana.com/about-invokana/what-is-invokana?

5. http://tech.cochrane.org/revman/about-revman-5

6. Bays HE, Weinstein R, Law G, Canovatchel W (2014) Canagliflozin: Effects in overweight and obese subjects without diabetes mellitus. Obesity 22:10421049.

7. Bode B, Stenlöf K, Harris S, Sullivan D, Fung A, et al. (2015) Long-term efficacy and safety of canagliflozin over 104 weeks in patients aged 55-80 years with type 2 diabetes. Diabetes Obes Metab 17:294-303.

8. Bode B, Stenlöf K, Sullivan D, Fung A, Usiskin K (2013) Efficacy and Safety of Canagliflozin Treatment in Older Subjects With Type 2 Diabetes Mellitus: A Randomized Trial. Hosp Pract 41:72-84.

9. Cefalu WT, Leiter LA, Yoon K-H, Arias P, Niskanen L, et al. (2013) Efficacy and safety of canagliflozin versus glimepiride in patients with type 2 diabetes inadequately controlled with metformin (CANTATA-SU): 52 week results from a randomized, double-blind, phase 3 non-inferiority trial. Lancet 382:941-950.

10. Chen X, Hu P, Vaccaro N, Polidori D, Curtin CR, et al. (2015) Pharmacokinetics, Pharmacodynamics, and Safety of Single-Dose Canagliflozin in Healthy Chinese Subjects. Clin Ther 37:1483-1492.

11. Devineni D, Morrow L, Hompesch M, Skee D, Vandebosch A, Murphy J, et al. (2012) Canagliflozin improves glycemic control over 28 days in subjects with type 2 diabetes not optimally controlled on insulin. Diabetes Obes Metab. 14:539-545.

12. Forst T, Guthrie R, Goldenberg R, Yee J, Vijapurkar U et al. (2014) Efficacy and safety of canagliflozin over 52 weeks in patients with type 2 diabetes on background metformin and pioglitazone. Diabetes Obes Metab. 16:467-477.

13. Inagaki N, Kondo K, Yoshinari T, Takahashi N, Susuta $\mathrm{Y}$, et al. (2015) Efficacy and safety of canagliflozin monotherapy in Japanese patients with type 2 diabetes inadequately controlled with diet and exercise: a 24-week, randomized, double-blind, placebo-controlled, Phase III study. Expert Opin Pharmacother 15:1501-1515.

14. Inagaki N, Kondo K, Yoshinari T, Maruyama N, Susuta Y, et al. (2013) Efficacy and safety of canagliflozin in Japanese patients with type 2 diabetes: a randomized, double-blind, placebo-controlled, 12-week study. Diabetes Obes Metab. 15:1136-1145.

15. https://www.invokana.com/about-invokana/what-is-invokana?

16. Ji L, Han P, Liu Y, Yang G, Van NKD, et al. (2015) Canagliflozin in Asian patients with type 2 diabetes on metformin alone or metformin in combination with sulphonylurea. Diabetes Obes Metab Diabetes Obes Metab. 17:23-31.

17. Lavalle-González FJ, Januszewicz A, Davidson J, Tong C, Qiu R, et al. (2013) Efficacy and safety of canagliflozin compared with placebo and sitagliptin in patients with type 2 diabetes on background metformin monotherapy: a randomized trial. Diabetologia. 56:2582-2592.

18. Polidori D, Sha S, Heise T, Natarajan J, Artis E, et al. (2015) Effect of canagliflozin, a sodium glucose co-transporter 2 inhibitor, on C-peptide kinetics. Clin Pharmacol Drug Dev 4:12-27.

19. Rosenstock J, Aggarwal N, Polidori D, Zhao Y, Arbit D, et al. (2012) DoseRanging Effects of Canagliflozin, a Sodium-Glucose Cotransporter 2 Inhibitor, as Add-On to Metformin in Subjects With Type 2 Diabetes. Diabetes Care 35:1232-1238.

20. Schernthaner G, Gross J, Rosenstock J, Guarisco M, Fu M, et al. (2013) Canagliflozin compared with sitagliptin for patients with type 2 diabetes who do not have adequate glycemic control with metformin plus sulfonylurea: a 52 week randomized trial. Diabetes Care 36:2508-2515.

21. Sha S, Polidori D, Heise T, Natarajan J, Farrell K, et al. (2014) Effect of the sodium glucose co-transporter 2 inhibitor canagliflozin on plasma volume in patients with type 2 diabetes mellitus. Diabetes Obes Metab 16:1087-1095.

22. Stenlöf K, Cefalu WT, Kim K-A, Alba M, Usiskin K, et al. (2013) Efficacy and safety of canagliflozin monotherapy in subjects with type 2 diabetes mellitus inadequately controlled with diet and exercise. Diabetes Obes Metab. 15:372 382 .

23. Wilding JPH, Charpentier G, Hollander P, González-Gálvez G, Mathieu C, et al. (2013) Efficacy and safety of canagliflozin in patients with type 2 diabetes mellitus inadequately controlled with metformin and sulphonylurea: a randomized trial. Int J Clin Pract 67:1267-1282. Yale J-F, Bakris G, Cariou $B$, Yue D, David-Neto E, et al. (2013) Efficacy and safety of canagliflozin in subjects with type 2 diabetes and chronic kidney disease. Diabetes Obes Metab. 15:463-473.

24. Tucker M (2015) FDA Strengthens Fracture Warning for Canagliflozin. Medscape.

25. Staab JF (1999) Adhesive and Mammalian Transglutaminase Substrate Properties of Candida albicans Hwp1. Science. 5407:1535-1538.

26. Geerlings S, Fonseca V, Castro-Diaz D, List J, Parikh S (2014) Genital and urinary tract infections in diabetes: Impact of pharmacologically-induced glycosuria. Diabetes Res Clin Pract 103:373-381. 